\section{PAH biomarkers for human health risk assessment: a review of the state-of-the-art}

\author{
Biomarcadores de HPAs na avaliação de risco à \\ saúde humana: uma revisão do estado da arte
}

\author{
${ }^{1}$ Faculdade de Saúde \\ Pública, Universidade de São \\ Paulo, São Paulo, Brasil. \\ Correspondence \\ S. S. Franco \\ Departamento de Saúde \\ Ambiental, Faculdade de \\ Saúde Pública, Universidade \\ de São Paulo. \\ Av. Dr. Arnaldo 715, \\ São Paulo, SP \\ 01246-904, Brasil. \\ francoss@usp.br
}

\begin{abstract}
Polycyclic aromatic hydrocarbons (PAH) are widely distributed in the environment, and some are carcinogenic to human beings. The study of biomarkers has helped clarify the nature and magnitude of the human health risks posed by such substances. This article provides a review of the state-of-the-art on PAH biomarkers for human health risk assessment and also discusses their applicability within the context of environmental management in Brazil. The article discusses the methodologies for determination of some biomarkers such as 1-hydroxypyrene and PAH-DNA adducts. Cytogenetic markers, frequency of chromosomal aberrations, and micronucleus induction were considered for the evaluation of cancer risk. The current stage of studies on validation of such biomarkers was also approached.
\end{abstract}

Aromatic Polycyclic Hydrocarbons; Biological Markers; Risk Assessment
Sérgio Silveira Franco 1

Adelaide Cássia Nardocci 1

Wanda Maria Risso Günther 1

\section{Introduction}

Knowledge of human health risks related to environmental exposure to hazardous chemical agents is a current concern. The majority of situations involve exposures to low doses for long periods, which in many cases involve the individual's entire lifetime and result in small increments in health risks.

In environmental exposures, traditional epidemiological approaches evaluating mortality and morbidity indicators display the following limiting factors: non-specificity of biological effects; latency time between exposure and magnitude of the effect, principally for carcinogenic effects; and limitations of epidemiological studies for detecting small risk increments.

Thus, other methods have been investigated to better detect associations between conditions of exposure to toxic agents and human health risks. Among these, biomarkers have been considered promising and have received the greatest attention in studying populations exposed to chemical contaminants. The World Health Organization (WHO) ${ }^{1}$ defines biomarker as any substance, structure, or process that can be measured within an organism or its products and influences or predicts the incidence of harmful effects or disease.

Biomarkers can be measured after exposure to food, environmental, or occupational sources to elucidate dose-effect relations in risk assess- 
ment, clinical diagnosis, and other forms of monitoring 2 .

Biomarkers are classified in three categories: (i) biomarkers of exposure, which involve detection and measurement of an exogenous substance, metabolite, or product of interaction between the xenobiotic and some molecule or target cell; (ii) biomarkers of effect, including measurement of biochemical and physiological alterations that can be related to the occurrence of disease or harm to health; and (iii) biomarkers of susceptibility, indicative of an organism's inherent or acquired ability to respond to the challenge of exposure to xenobiotics.

The integrated application of epidemiological studies, environmental behavior of contaminants, and biomarkers can provide more solid data in relation to the human health risks resulting from environmental exposure to chemical substances like polycyclic aromatic hydrocarbons (PAH). The widespread distribution of $\mathrm{PAH}$ in the environment associated with various human activities, especially burning of fossil fuels, has raised concerns over the impacts of health exposures, especially in urban areas. Some PAH are now recognized as carcinogens or probable carcinogens for human beings and other mammals. Recent studies demonstrate that $\mathrm{PAH}$ with more than three aromatic rings account for $70-90 \%$ of the total carcinogenic effect related to these sources, thus posing a serious health threat ${ }^{3}$.

Investigation of the sequence of events beginning with exposure to potentially harmful substances and culminating with the increase in morbidity and mortality events is a challenge for public health research. In this context, the use of biomarkers is a promising approach.

However, research on biomarkers has still not reached these objectives. According to Bonassi et al. 4 , confusing and sometimes conflicting results have been obtained from studies on the exposed population. In this sense, it has only proven possible to intervene successfully in the development of disease or to increase the capacity to detect low doses of given substances or mixtures of different agents in some specific situations.

The recognition of these limitations and the need for prior validation of biomarkers before their application motivated the current study, the objective of which was to characterize the state of the art in studies on PAH biomarkers in settings involving environmental exposure and the current requirements for validation, aimed at backing the use of these biomarkers in environmental risk assessment. We also conducted a critical analysis of the applicability of biomarkers for risk assessment in the context of environmental management in Brazil.

\section{Methodology}

The material for this review was obtained from the Electronic Reference Library (ERL), using WebSPIRS from SilverPlatter Information (Ovid Technologies, New York, USA; http://www.ovid. $\mathrm{com} / \mathrm{site} / \mathrm{products} /$ tools/silverplatter/sp_web spirs.jsp?top $=2 \& \operatorname{mid}=3 \&$ bottom $=8 \&$ subsection $=14$ ).

To select the most relevant databases for the study subject, we conducted a search for the free term (biomarker* OR biological marker*) AND (polycyclic aromatic hydrocarbon). This survey allowed us to verify which databases contained articles on the respective subject. The selected databases were: MEDLINE, Biological Abstracts, Aquatic Sciences and Fisheries Abstracts (ASFA), Zoological Records, and CAB Abstracts. A total of 423 articles were found in these databases, distributed as follows: 151 articles in PubMed Online, 108 in MEDLINE, 96 in Biological Abstracts, 33 in ASFA, 22 in Zoological Records, and 13 CAB Abstracts.

Of all the articles located, we selected those published from 1995 to 2005 that approached the use of biomarkers for the assessment of PAH effects, with special emphasis on articles that presented previously validated methodologies and those aimed at validating new methodologies and approaches. Other articles not directly related to the specified theme were discarded. Some articles prior to the specified period were included because they were considered relevant to the subject under discussion. To determine the study's relevance and decide on its inclusion or exclusion, the available abstracts were read, and after selection of the studies directly related to the theme, a search was made for the full texts, which were then considered in the present review.

After obtaining the full texts, the analysis phase was performed, consisting of grouping the information on the available types of PAH biomarkers and verifying the situation of the studies conducted until the time of the review.

\section{Human exposure to PAH}

PAH are binary substances formed by carbon and hydrogen and constituting a subclass of polycyclic aromatic compounds (PACs); the latter are organic compounds containing two or more fused aromatic rings, that can be arranged in a straight line, angled, or in clusters. As an overall characteristic, this class of compounds presents low vapor pressure and high melting and boiling points and very limited solubility in water, which tends to decrease with the increase in molecular 
mass. Environmentally relevant sources of PAH are: smoking, fossil fuel combustion, vehicle exhaust, and use of lubricant oils. PAH are used as intermediate substances in the production of plasticizers, pigments, drying agents, and pesticides, but the environment probably receives only small amounts as a direct result of these activities; the most significant emissions are from incomplete combustion of organic materials during industrial processes and other anthropogenic activities 5 .

There are more than different $100 \mathrm{PAH}$, generally present in complex mixtures and not as a single substance 6 , of which 16 are classified by the U. S. Environmental Protection Agency as priority pollutants for environmental investigation: acenaphthene, acenaphthylene, anthracene, benzo[a]anthracene, benzo[a]pyrene, benzo[b]fluoranthene, benzo[g,h,i]perylene, benzo[k]fluoranthene, chrysene, dibenzo[a,h] anthracene, phenanthrene, fluoranthene, fluorene, indeno[1,2,3-c,d]pyrene, naphthalene, and pyrene 6 .

According to the U.S. Agency for Toxic Substances \& Disease Registry (ATSDR) 7, background atmospheric values of some representative $\mathrm{PAH}$ vary from 0.02 to $1.2 \mathrm{ng} / \mathrm{m}^{3}$ in rural areas and 0.15 to $19.3 \mathrm{ng} / \mathrm{m}^{3}$ in urban areas. In countries like Italy and Germany, reference values vary from 1 to $10 \mathrm{ng} / \mathrm{m}^{3}$, frequently exceeded in urban areas. In Brazil, there are also studies on environmental levels in some urban areas 8,9,10.

Human exposure can occur in indoor or outdoor environments and by all routes (inhalation, ingestion, and skin contact), regardless of the source. PAH formed by burning of fossil fuels, smoke from forest fires, and cigarette smoking are mainly available for inhalation, but they can also be ingested together with food (e.g., smoked foods, atmospheric deposition on vegetables, and coal used for cooking) or saliva (smoking). For skin contact, the principal primary sources are exposure to tar, soot, and organic solvents 11.

In the human body, since PAH are lipophilic substances, they are readily dissolved and transported by cell membrane lipoproteins. The absorption rate depends on the specific PAH 12 . In general, they are distributed throughout the body and found in any internal organ or tissue, particularly in lipid-rich tissues and the gastrointestinal tract, through the reabsorption of the product of hepatobiliary excretion 5 .

Experimental animal studies have demonstrated that some PAH cause tumors in case of oral or cutaneous exposure. In food exposure, effects have been found in the reproductive system related to fertility, problems during pregnancy, and congenital anomalies 7 . Epidemiological studies have also shown the relevant role of PAH in carcinogenesis 3,13 .

\section{PAH biomarkers}

Advances in analytical theories allow measuring increasingly lower concentrations of chemical substances in the environment. Meanwhile, epidemiological studies face difficulties in establishing correlations between these exposures and effects on human health. In such situations, the sensitivity of biomarkers allows detection and measurement at reduced concentrations, thus expanding the reach of dose-response studies for assessing sub-lethal effects 1,14.

The quantity of substances monitored depends on the medium sampled, the objectives, and the available resources. Exposures are generally proportional to the PAH concentrations in the environment. Environmental assessment of $\mathrm{PAH}$ mixtures can be based on one that is representative of the group, like benzo[a]pyrene or a group of PAH - benzo[a]anthracene, chrysene, benzo[b]fluoranthene, benzo[k]fluoranthene, benzo[a]pyrene, dibenzo[ah] anthracene, benzo [ghi]perylene, and indeno[1,2,3-cd]pyrene 15 .

After the substance enters the body, the unaltered (parental) substance or its metabolites are searched for in the urine, blood, feces, or other bodily fluids or tissues. Since parental PAH generally present a reduced plasma half-life, hydroxyl metabolites are the most frequent option for investigation.

PAH metabolism into more soluble forms is a necessary step for their excretion. The parental compound is generally oxidized by phase 1 enzymes through hydroxylation catalyzed by cytochrome P450 monooxygenase enzymes; hydrolysis and reduction can also occur. These phase I metabolites bind to glutathione, sulfates, or glucuronic acid to form phase II metabolites in order to form more polar and water-soluble substances than the original substances, thereby greatly facilitating their excretion. The metabolites and conjugates are excreted via the urine and feces, but conjugates excreted in bile can be reabsorbed in the intestine. The hydroxyl metabolites can be used as biomarkers based on their ability to indicate the internal dose received 3 .

The majority of these reactions result in detoxification, but compounds can be produced that are highly reactive as electrophilic $\mathrm{PAH}$ metabolites, which can form covalent interactions with proteins and nucleic acid, resulting in adducts that can compromise normal cell functioning, triggering a series of harmful effects 3,5,15. 
Hydroxyl PAH metabolites: biomarkers of internal dose

Metabolites excreted in the urine provide more appropriate estimates of total ingestion as compared to exposure assessments based on environmental data. The choice of the urinary metabolite should consider the constituent of the most common PAH. In cases of complex mixtures, more than one biomarker should be considered to ensure adequate evaluation. 1-hydroxypyrene is the most widely used metabolite in PAH exposure, since pyrene is one of the most abundant hydrocarbons in all PAH mixtures and has as its principal metabolite 1-hydroxypyrene formed in mammals $3,16,17$, thus representing a sensitive biomarker of exposure, recommended by various authors as the most relevant parameter in estimates of individual exposure to PAH 1,17,18,19,20,21. Smoking is monitored with cotinine (a hydroxyl metabolite of nicotine), which allows controlling this intervening variable in studies on environmental PAH exposure 3,15.

Human monitoring studies describe the halflife of urine 1-hydroxypyrene as varying from 4 to 48 hours, and the time between exposure and sample collection is an important factor. In environmental exposures, 24-hour urine samples express the best correlation with concentrations. Since environmental concentrations can vary, it is necessary to characterize the exposure pattern for each situation and study population, by identifying the environmental pyrene concentrations and background 1-hydroxypyrene 15,17 values, measured in a reference group.

\section{PAH-DNA: biomarkers of effective dose}

PAH play an undeniable role in the induction of human carcinogenesis. There is evidence on the transformation of healthy cells into cancer cells, using in vitro cell culture experiments, animal studies, and in vivo studies with occupationally or environmentally exposed healthy human volunteers and cancer patients 9 .

Chemical induction of carcinogenesis is a complex process; multiple stages involve mutations in cell growth-regulating genes (proto-oncogenes) and tumor-suppressor genes 13,15,22.

DNA adducts have proven to be promising biomarkers, since they consider individual differences in exposure, absorption, and distribution of chemical agents, metabolism to DNA-reactive forms, detoxification in reactive intermediaries, and cell replacement and repair of DNA damage. DNA adducts are used to assess both exposure and cancer risk in humans.
However, use in humans is limited by ethical issues, since most target organs for PAH-induced carcinogenesis are not accessible by routine sample; therefore, studies used surrogate tissues, with easily obtained cells like circulating leukocytes 13 . However, this practice has been criticized, since surrogate cells are not always targets for PAH or the most sensitive for the formation of adducts, thus potentially compromising the reliability of in vivo studies. Conflicting results have been found in relation to the formation of PAH-DNA adducts in leukocytes. Some studies on occupational exposure indicate the occurrence of these adducts in unexposed individuals as well 13,23; studies in groups of smokers failed to show significant alteration in comparison to the control group, suggesting a source other than smoking 13,24; other studies show that dermal exposure and ingestion of PAH may be more significant than inhalation in the formation of adducts in circulating leukocytes 13,25.

An evaluation of different leukocytes subpopulations is necessary for the correct interpretation of the contribution of the exposure routes involved, to minimize difficulties in correlating adduct levels in target organs and those observed in circulating cells. Phillips et al. 24 failed to show a relationship between DNA adducts in leukocytes and lung cells. Other more recent studies only indicate a correlation with mononuclear cells, showing that adducts in leukocyte cell fractions may reflect adduct levels in relevant target organs and be used to monitor and evaluate cancer risk. The life span of lymphocytes (days to year) may qualify these cells for evaluating long-term exposures, while monocytes and granulocytes (hours and days) only represent more recent exposures, thus compromising estimates of adducts in total leukocytes. It is thus necessary to intensify characterization studies involving leukocytes in order to generate detailed information on the abovementioned conflicting data.

Other cells have been used, like alveolar macrophages, cells obtained from bronchoalveolar lavage 26 , easily obtained by sputum induction, an easily applicable and relatively non-invasive technique ${ }^{27}$. The highest DNA adduct levels were observed, respectively, in: alveolar cells, circulating mononuclear monocytes, and granulocytes, suggesting that measuring adducts in these first two cells allows a more sensitive analysis in the evaluation of exposures to inhaled PAH 13.

The relationship between PAH exposure and formation of adducts has been used to assess the applicability of DNA adducts to distinguish between two or more exposure levels 13, aimed at providing the basis as an ancillary methodology for exposure estimates. 
Studies in animals show a strong dose-response relationship in exposures to low doses, which is not always found in humans. Lung tissue from smokers showed a correlation between adduct levels and number of cigarettes per day, but the dose-response curve tends to level off at high doses ( $>20$ cigarettes/day) 28. Different individuals exposed to similar levels present variations in the levels of adducts formed, probably due to the genetic polymorphism in the enzymes involved in the activation or detoxification of $\mathrm{PAH}$ and the DNA repair mechanism. This variation accounts for differences in susceptibility to the development of cancers; various studies have focused on the identification of the genes responsible for such differences 13,29,30. Variations are also observed within and between individuals and are related mainly to intermittence in the exposure pattern, in addition to action by other intervening factors such as: smoking, differences in eating patterns, and seasonal differences in the bioavailability of the substances. Thus, intra and inter-individual variations must be characterized before applying PAH-DNA adducts as markers of exposure in large-scale studies 13,29,30,31.

\section{Cytogenetic alterations: biomarkers of early effect}

In cell cultures of peripheral lymphocytes, cytogenetic alterations like chromosomal aberrations, sister chromatid exchange, and micronucleus induction have been applied as biomarkers of exposure and early effect in exposures to genotoxic carcinogens 30,32 .

Like the majority of biomarkers for genotoxicity, cytogenetic alterations in lymphocytes are estimates obtained from surrogate tissues, presuming that they represent more specific chromosomal alterations, important in the carcinogenesis of target tissues. Evidence has been found in studies showing the high frequency of chromosomal aberrations, but not chromatid exchange or micronucleus induction in peripheral lymphocytes as predictive parameters of increased cancer risk 15,30,33,34.

The relevance of increased frequency of cytogenetic alterations as biomarkers of cancer risk has been corroborated by epidemiological studies suggesting the high frequency of chromosomal aberrations as the best predictive parameter for increased cancer risk.

\section{Genetic polymorphism: biomarkers of susceptibility}

Genetic polymorphisms have received increasing attention, since they can modulate the hu- man response to exposures to genotoxic agents, whose role in susceptibility can be studied more easily through the use of biomarkers like cytogenetic alterations $30,35,36$.

Studies on genetic polymorphism depend on: the biological material examined and the exposure and ethnic composition of the study population. Since cytogenetic markers can represent exposures that occurred months before the tissue sampling, simple measurements of urinary metabolites or environmental concentrations may not be representative of the most relevant exposure period. For different exposure levels, the exposed individuals should be grouped in distinct categories and compared to the control group to allow distinguishing exposure-genotype interactions from background biomarker levels 30 .

Another important factor is the expression of genotype differences in the cell or tissue examined. As an example, the enzymes glutathione-s-transferase M1 (GSTM1) and T1 (GSTT1) detoxify various reactive chemical agents and are expressed in leukocytes and erythrocytes 30. Individuals that possess at least one copy for the alleles GSTM1 A or GSTM1 B possess GSTM1 activity, but homozygotes for the deletion of the GSTM1 gene (GSTM1-null genotype) do not present this activity 37 . The frequency of the GSTM1-null genotype is approximately $50 \%$ in the Caucasian population 36 . Likewise, the homozygous deletion of gene GSTT1 (GSTT1null genotype), found in 13-28\% of Caucasians, makes them unable to perform GSTT1-mediated detoxification 30,37 . Consequently, high rates of cytogenetic damage induced by genotoxic substances can be expected in cells of GSTM1 and T1-null individuals, which totally lose their respective enzymatic activities 30 .

Knudsen et al. 38 observed that GSTM1-null bus drivers (non-smokers) exposed to urban air pollution show a high frequency of chromosomal aberrations as compared to GSTM1-positive drivers. Other studies of DAN adducts have suggested that the GSTM1-null DNA genotype predisposes carriers to increased genotoxic effects from PAHpolluted air 30,39,40,41. Such studies observed that the frequency of micronucleus induction in lymphocytes only correlates with the level of DNA adducts in GSTM1-null individuals.

Many of the monooxygenase enzymes - cytochrome P450 - are polymorphic, and some genotypes are associated with high enzymatic activity, so that high induction is expected when exposed to chemical agents. The principal variant alleles in the cytochrome P450 1A gene (CYP1A1) include alleles 2A, 2C, 2B, and 4 42. Studies are limited on the effect of cytochrome $\mathrm{P} 450$ polymorphism on chromosomal damage, and their 
interpretation is complicated by the limited clarity of associations between the cytochrome P450 genotype and the phenotypical expression of rare variant alleles 30 .

High levels of chromosomal aberrations in peripheral lymphocytes have been observed for the prediction of increased cancer risk for smoking and occupational exposure. Various polymorphisms in enzymes for the metabolism of xenobiotics have indicated an inductive effect on cytogenetic biomarkers 30 .

The importance of various genetic polymorphisms in determining the level of cytogenetic alterations depends on the following factors: cytogenetic parameter, chemical agent, and ethnic composition of the study population. Cytogenetic biomarkers can be used to identify sub-groups that are sensitive to carcinogens.

\section{Validation}

Validation of a biomarker is a set of necessary procedures for reliable extrapolation, to real conditions, of data obtained under experimental conditions. According to the WHO 1, validity refers to the biomarker's accuracy; it is a complex characteristic that describes the extent to which the biomarker reflects a specific event in a biological system.

A biomarker can only be used systematically after experimental and epidemiological validation 1,43 . In experimental research, validity refers to the nature of the biomarker and the assay's necessary characteristics for the determination of its levels, presence, and/or activity, as well as to the essay's sensitivity for detecting response at a known concentration and specificity for a given particular event. Epidemiological studies use experimental validity data as the basis for studies in human populations; they also examine their feasibility for use in humans, sensitivity and specificity for population groups, and the assay's reliability under field conditions.

Bonassi et al. ${ }^{4}$ presented a general proposal for validation of biomarkers for human health risk assessment, consisting of three interdependent phases: development of the biomarker, characterization, and longitudinal studies.

During the development phase of the biomarker, parameters are evaluated for performing the assay: stability, reliability, sensitivity, and specificity, in addition to adequate procedures for collecting and preserving samples 1,44,45,46.

Characterization of the biomarker examines its variability in population subgroups and measures the impact of potential confounders in the association between biomarker and bio- logical event. Longitudinal studies evaluate the relationship between frequency of the biomarker and disease incidence, based on observational studies ${ }^{4}$.

Development of biomarkers is facilitated when data from observational studies of humans are linked to experimental studies with animals and in vitro cell lines 1 .

\section{Application of biomarkers to environmental risk assessment}

Until recently, damage to health resulting from environmental factors was mainly identified on the basis of retrospective studies $47,48,49$ based on responses to acute events like accidents and occupational exposures.

However, chronic exposures rarely result in rapid and easily observable change. The impact is almost always gradual and subtle, and it frequently becomes difficult to distinguish between natural environmental changes and impacts from other sources; the time scale for such events is on the order of decades, thus making retrospective studies complicated 49 .

In this sense, increasing efforts have focused on risk assessment studies based on models and data for environmental concentrations of the contaminants, a tool already widely adopted in various countries. Environmental risk assessment is understood as consisting of four stages: identification of hazards; evaluation of exposure; dose-response assessment; and risk characterization 50 . Such studies are based on information from experimental toxicity studies and physical and chemical characteristics of the substances and their behavior in the environment.

The main advantages of risk assessment are: low cost, lack of need for population interventions; and possibility for use in the assessment of postulated exposure settings, not depending on the existence of real situations of human exposure. However, they are heavily dependent on the existence of toxicological data and models that are not always reliable, especially for low doses, and they do not adequately assess exposure to mixtures of contaminants in fluctuating conditions prevailing in the environment 50 .

Recent studies on human exposure to environmental contaminants have incorporated laboratory analytical techniques into epidemiological inventories to elucidate the biochemical or molecular basis for the etiology of diseases, thus providing useful information like internal dose and biological effects, using biomarkers 51 .

Evaluation of chromosomal aberrations and micronucleus induction as intermediate param- 
eters in cross-sectional studies to assess DNA damage can provide insights on mechanisms in the exposure-disease relationship, to supplement evidence (even though non-conclusive) of carcinogenicity. They can also evaluate whether chromosomal damage is related to new exposures that do not present sufficient time to be evaluated by means of association with cancer incidence, based on longitudinal studies 52 .

However, caution is needed in interpreting these parameters, since a positive association between exposure and frequencies of chromosomal aberrations and micronucleus can be informative, but null association does not guarantee the absence of carcinogenic effect 52 .

The advantage of applying biomarkers to cross-sectional studies is the possibility of obtaining detailed and accurate information on: current exposure pattern, possible confounders, and specific effects 32,53 . However, processing blood and urine samples for the analysis of chromosomal aberrations and micronucleus is toilsome, and the simultaneous evaluation of a large number of samples can be problematic 52 .

Thus, many studies present relatively small samples ( $\mathrm{n}<100$ individuals), thereby compromising studies of exposures at low doses, which require larger samples.

Many samples require complex logistics, including cryopreservation of total blood or lymphocytes isolated for subsequent analysis, which can introduce an adverse effect on the study. Hayes et al. 54 demonstrated the recovery of viable lymphocytes from cryopreserved total blood, while others have only shown success with the cryopreservation of isolated lymphocytes 55 . It has also been demonstrated that cryopreservation of samples can induce an increase in chromosomal aberrations and a decrease in cell viability 56 .

The use of chromosomal aberrations and micronucleus in prospective cohort studies, adequate for validation since they furnish important information on causality in the dose-response relationship, has been applied in limited fashion, mainly to validate evaluation of exposure 52 .

While cohort studies have serial sample collection over time as their theoretical advantage, in practice very long studies impose limitations on sample collection and preservation, thus involving some restrictions. Chromosomal aberrations and micronucleus, as well as the principal genetic aberrations, only reflect the most recent months of exposure, which may not be representative for the exposure and/or disease under investigation 52 . In this case, the study of translocations may be more adequate, since they are genetic alterations that persist for decades 53 .
Cohort studies with chromosomal aberrations and micronucleus as early parameters for cancer risk in human populations have been performed mainly using the ad hoc method 52,57 . Investigation based on samples obtained from several smaller biomonitoring studies are limited by differences in the respective analytical techniques, lack of detailed information on confounding, and possible specific effects in the sampled populations 52 .

Other factors like technological innovation and validation of early parameters for cancer prediction are directing the expansion of application of cytogenetic biomarkers.

The development of analytical techniques has transformed the applications of assays, which are currently capable of providing valuable information on early stages of chronic diseases, especially cancer 52 .

Likewise, the study of interphase cells has transformed the micronucleus assay, not only into a rapid and simple test for genotoxicity, but as a tool to evaluate important events like gene amplification 58 .

The most obvious advantages expected in the coming years with the use of biomarkers include increased reliability in the evaluation of exposure and detection of early damage in populations exposed to reduced levels or complex mixtures of genotoxic agents. The identification of genetic variations linked to chromosomal damage is increasing the sensitivity and power of these studies, facilitated by the reduction in the costs of molecular techniques and increased use of automation, which will allow studies of large populations, increasing the sensitivity for detecting effects of exposure 52 .

Importantly for the validation of cytogenetic biomarkers as early parameters for cancer prediction, the causal relationship between chromosomal aberrations and cancer risk has been described in cohort studies 59 .

In recent years, many international studies have focused on the effects of environmental pollutants in children, and molecular epidemiological studies have provided new perspectives in pediatric populations, increasingly supporting the widely known fact that children are more susceptible than adults to toxic substances 60 .

Two recent reviews by Neri et al. 60,61 have shown that biomarkers of genetic damage are capable of detecting early biological effects in exposed children and newborns and are consistently increased in pre and postnatal exposures to cigarette smoke, and in postnatal exposures to urban air pollution. Thus, these studies suggest that biomonitoring programs benefit from including biomarkers. 
The application of cytogenetic biomarkers to the prediction of cancer risk in healthy individuals is a considerable challenge. Uncertainties in risk prediction at the individual level and the complexity of ethical issues are factors that could delay the design and planning of studies 52 . Nevertheless, it is already possible to use validated biomarkers as instruments for prevention policies and programs for characterization of effects in high-risk populations. Chromosomal aberrations and micronucleus are sufficiently consolidated for application in cross-sectional studies, aimed at characterizing early carcinogenic effects 52 .

The application of cytogenetic biomarkers for screening individuals is of the utmost importance, since it represents the necessary step for establishing surveillance programs applicable to national regulations for occupational and environmental safety 52 .

\section{Critical analysis of the application of biomarkers for environmental management in Brazil}

The current approach to environmental management in Brazil focuses on the identification and control of sources of pollution based on their compliance with pollutant emissions and environmental quality standards. Health is always the greater good to be protected, and values and standards are always set with a view towards guaranteeing adequate levels of protection for human and ecosystem health. Brazil still experiences difficulties in defining quality criteria and standards compatible with the national reality and environmental specificities; the reference values are nearly always imported, without a more in-depth analysis of their environmental, social, and health implications for the Brazilian population.

However, recent studies in the United States have demonstrated this model's weakness in relation to the control of human exposures to environmental contaminants and reduction of health risks. According to Steinemann ${ }^{62}$, recent studies by the USEPA, the Centers for Disease Control and Prevention (CDC), and the Mount Sinai School of Medicine in New York show that persons are more exposed in internal versus external environments, due to the significant contribution of household cleaning and hygiene products. For example, exposure to volatile organic compounds (VOCs) in internal environments is 5-10 times greater than external exposure, even in urban areas with high pollution and intense industrial activity.
Meanwhile, rates of diseases that may be associated with exposure to chemical substances have increased significantly in recent years throughout the United States. According to Steinemann 62, cancer in children increased by $26 \%$ from 1975 to 1999, highlighting acute lymphocytic leukemia (62\%) and cancers of the central nervous system and brain (50\%). Testicular cancer in young men increased 85\% (1973-1999) and is already the most common type of cancer among men 15-35 years of age. According to the American Cancer Society, only $5-10 \%$ of all cancers can be attributed to endogenous factors, while the rest are caused by environmental factors.

These studies demonstrate the need to redirect the current focus of environmental regulations in the sense of prioritizing not only environmental quality control but also the effective assessment of human exposure to contaminants. In this context, studies of biomarkers gain relevance to the extent that they allow not only exposure assessment but also prediction of effects and human health risk.

However, as verified in this study, the use of biomarkers in environmental risk assessment studies requires prior and reliable databases and information, not only to identify the situations in which the biomarker can contribute to the understanding of the exposure-disease processes, but also to increase the credibility of its results. Although these studies with biomarkers have generated a significant amount of information to back their utilization, consistent criteria are necessary concerning the prior characterization of the study area and population in order to use them adequately and produce reliable results.

Furthermore, studies with biomarkers may not be feasible for large or ethically restricted populations, since sample collection in humans can only be performed with strict compliance to ethical principles and with prior informed consent of subjects.

Based on the above, some important considerations are in order from the perspective of using biomarkers for management of environmental problems in Brazil:

- Despite advances in environmental management, there are still great difficulties to be overcome, especially in relation to environmental information systems in the country. For example, air pollution control, even in metropolitan areas, only considers the basic indicators, and there are no data on environmental concentrations of other toxic pollutants. Neither are there reliable inventories of industrial installations and pollutant emission levels that could provide the basis for identification, through mathematical models, 
of critical exposure areas, where studies on biomarkers could be performed;

- In most Brazilian States, there is still no inventory of contaminated areas. In the State of São Paulo, which already has a methodology for identification/management and a periodically updated registry of these areas, little or no information exists on human exposure there, even in the areas have already subjected to remediation;

- Another relevant aspect is the development of closer collaboration between environmental and health agencies and the establishment of integrated information systems to jointly support the definition of integrated and more effective policies and actions in the interface between health and the environment;

- Expansion of the scope of activity by institutions to encompass studies of human exposure evidently means not only formal expansion, but also an increase in current investments for training human resources and implementing the necessary infrastructure;

- The use of biomarkers, when compared with methods based on the definition of standards, can initially be more difficult to apply and entail a higher cost. However, measurement of environmental concentrations alone does not guarantee the absence of adverse effects for human health;

- Despite difficulties in the development of characterization studies, especially in Brazil (with limited resources and infrastructure), the possibility of understanding local specificities is precisely the greatest advantage of biomarkers, constituting an important tool for the evaluation of effectiveness (or lack thereof) in the prevailing standards, allowing the assessment and adjustment of their values and providing more reliable responses to the human and ecosystem health conditions.

\section{Conclusion}

Analysis of the recent literature shows that the application of biomarkers to environmental risk assessment, especially for human health, has expanded continuously thanks to the advances obtained in characterization and validation studies, although their utilization depends on consistent criteria for defining the study area and population. The limited number of studies published in Brazil, including the reviews by Lopes et al. 63 and Pereira Netto et al. ${ }^{64}$, indicate the need for greater incentives and institutional support to foster the use of this approach in the national context.

For assessing human exposure to $\mathrm{PAH}$, recent validation studies highlight urinary 1-hydroxypyrene as a methodology already validated for monitoring exposure and PAH-DNA adducts in lymphocytes as a marker of effective dose. The most promising biomarkers still in the validation process include cytogenetic markers of early effect, evaluation of frequency of chromosomal aberrations, and micronucleus induction.

Future prospects for application of biomarkers to environmental risk assessment of PAH exposure are promising. The expected advances for the coming years are: increased reliability in the exposure assessment and detection of early harm in populations exposed to low doses and to the mixture of chemical substances; increased sensitivity of these studies for the identification of genetic variations linked to chromosomal damage; reduction in the cost of molecular techniques; and increased use of automation.

Importantly, biomarkers represent key prospects for expanding scientific research in the environmental health field. However, in the field of science as well, some barriers between areas of knowledge need to be eliminated in order to ensure the interdisciplinarity these studies require, especially in relation to the recognition of the environmental area as an important field in public health. 


\section{Resumo}

Os hidrocarbonetos policíclicos aromáticos (HPAs) estão amplamente distribuídos no ambiente e alguns são carcinogênicos para humanos. O estudo dos biomarcadores tem contribuído para a compreensão da natureza e magnitude dos riscos que estas substâncias representam à saúde humana. Este trabalho apresenta uma revisão do estado da arte dos biomarcadores de HPAs para avaliação de risco à saúde humana e analisa criticamente sua aplicabilidade, no contexto da gestão ambiental brasileira. Destaca as metodologias para a determinação de alguns biomarcadores como 1-hidroxipireno e adutos HPA-DNA. Para avaliação do risco de câncer destacam-se marcadores citogenéticos, freqüência de aberrações cromossômicas e indução de micronúcleo. Também é abordado o estágio atual dos estudos de validação desses biomarcadores.

Hidrocarbonetos Policíclicos Aromáticos; Marcadores Biológicos; Avaliação de Risco

\section{Contributors}

S. S. Franco conducted the study and elaborated the manuscript. W. M. R. Günther supervised the research and elaboration of the manuscript and collaborated in the revision. A. C. Nardocci co-supervised the research and contributed to the elaboration, drafting, and revision of the manuscript.

\section{References}

1. International Programme on Chemical Safety, World Health Organization. Biomarkers and risk assessment: validity and validation. Geneva: World Health Organization; 2001. (Environmental Health Criteria, 222).

2. van der Oost R, Beyer J, Vermeulen NPE. Fish bioaccumulation and biomarkers in environmental risk assessment: a review. Environ Toxicol Pharmacol 2003; 13:57-149.

3. Jacob J, Seidel A. Biomonitoring of polycyclic aromatic hydrocarbons in human urine. J Chromatogr B Analyt Technol Biomed Life Sci 2002; 778:31-47.

4. Bonassi S, Neri M, Puntoni R. Validation of biomarkers as early predictors of disease. Mutat Res 2001; 480:349-58.

5. International Programme on Chemical Safety, World Health Organization. Selected non-heterocyclic polycyclic aromatic hydrocarbons. Geneva: World Health Organization; 1998. (Environmental Health Criteria, 202).

6. Office of Air Quality Planning and Standards, U. S. Environmental Protection Agency. Handbook for air toxics emission inventory development. v. I: stationary sources. Research Triangle Park: U. S. Environmental Protection Agency; 1998. (EPA454/B-98-002).
7. Agency for Toxic Substances and Disease Registry. Toxicological profile for polycyclic aromatic hydrocarbons. Atlanta: Agency for Toxic Substances and Disease Registry; 1995.

8. Pereira Netto AD, Krauss TM, Cunha IF, Rego ECP. Polycyclic aromatic hydrocarbons levels in street dust in the central area of Niterói City, RJ, Brazil. Water Air Soil Pollut 2006; 176:57-67.

9. Pereira Netto AD, Barreto RP, Moreira JC, Arbilla G. PAHs in diurnal and nocturnal samples of total suspended particulate in a highly trafficked area of Rio de Janeiro City, Brazil. Bull Environ Contam Toxicol 2005; 75:1004-11.

10. Pereira Netto AD, Cunha IF, Muniz FC, Rego ECP. Polycyclic aromatic hydrocarbons in street dust of Niterói City, RJ, Brazil. Bull Environ Contam Toxicol 2004; 72:829-35.

11. Burchiel SW, Luster MI. Signaling by environmental polycyclic aromatic hydrocarbons in human lymphocytes. Clin Immunol 2001; 98:2-10.

12. Boström CE, Gerde P, Hanberg A, Jernström B, Johansson C, Kyrklund T, et al. Cancer risk assessment, indicators, and guidelines for polycyclic aromatic hydrocarbons in the ambient air. Environ Health Perspect 2002; 110:451-88. 
13. Godschalk RW, Van Schooten FJ, Bartsch H. A critical evaluation of DNA adducts as biological markers for human exposure to polycyclic aromatic compounds. J Biochem Mol Biol 2003; 36:1-11.

14. Ehrenberg L, Granath F, Törnqvist E. Macromolecular adducts as biomarkers of exposure to environmental mutagens in human populations. Environ Health Perspect 1996; 104:423-8.

15. Brandt HC, Watson WP. Monitoring human occupational and environmental exposures to polycyclic aromatic compounds. Ann Occup Hyg 2003; 47:349-78.

16. Jongeneelen FJ. Methods for routine biological monitoring of carcinogenic PAH-mixtures. Sci Total Environ 1997; 199:141-9.

17. Sorensen MAH, Moller P, Hertel O, Jensen SS, Vinzents P, Knudsen LE, et al. Linking exposure to environmental pollutants with biological effects. Mutat Res 2003; 544:255-71.

18. Viau C, Lafontaine M, Payan JP. Creatinine normalization in biological monitoring revisited: the case of 1-hydroxypyrene. Int Arch Occup Environ Health 2004; 77:177-85.

19. Tsai PJ, Shih TS, Chen HL, Lee WJ, Lai CH, Liou SH. Urinary 1-hydroxypyrene as an indicator for assessing the exposures of booth attendants of a highway toll station to polycyclic aromatic hydrocarbons. Environ Sci Technol 2004; 38:56-61.

20. Siwinska E, Mielzynska D, Kapka L. Association between urinary 1-hydroxypyrene and genotoxic effects in coke oven workers. Occup Environ Med 2004; 61:1-10.

21. Hansen AM, Wallin H, Binderup ML, Dybdahl M, Autrup H, Loft S, et al. Urinary 1-hydroxypyrene and mutagenicity in bus drivers and mail carriers exposed to urban air pollution in Denmark. Mutat Res 2004; 557:7-17.

22. Wünsch Filho V, Gattás GJF. Biomarcadores moleculares em câncer: implicações para a pesquisa epidemiológica e a saúde pública. Cad Saúde Pública 2001; 17:467-80.

23. Peluso M, Ceppi M, Munnia A, Puntoni R, Parodi S. Analysis of 13 32P-postlabeling studies on occupational Cohorts exposed to air pollution. Am J Epidemiol 2001; 153:546-58.

24. Phillips DH, Schoket B, Hewer A, Bailey E, Kostic $S$, Vincze I. Influence of cigarette smoking on the levels of DNA adducts in human bronchial epithelium and white blood cells. Int J Cancer 1990; 46:569-75.

25. Herbert R, Marcus M, Wolff MS, Perera FP, Andrews L, Godbold JH, et al. Detection of adducts of deoxyribonucleic acid in white blood cells of roofers by $32 \mathrm{P}-$ postlabeling. Relationship of adduct levels to measures of polycyclic aromatic hydrocarbons. Scand J Work Environ Health 1990; 16:135-43.

26. De Flora S, Izotti A, D’Agostini F, Rossi GA, Balansky RM. Pulmonary alveolar macrophages in molecular epidemiology and chemoprevention of cancer. Environ Health Perspect 1993; 99:249-52.

27. Besaratinia A, Maas LM, Brouwer EM, Kleinjans JC, Van Schooten FJ. Comparison between smokingrelated DNA adduct analysis in induced sputum and peripheral blood lymphocytes. Carcinogenesis 2000; 21:1335-40.
28. Dallinga JW, Pachen DM, Wijnhoven SW, Breedijk A, van't Veer L, Wigbout G, et al. The use of 4-aminobiphenyl hemoglobin adducts and aromatic DNA adducts in lymphocytes of smokers as biomarkers of exposure. Cancer Epidemiol Biomarkers Prev 1998; 7:571-7.

29. Schoket B, Papp G, Levay K, Mrackova G, Kadlubar FF, Vincze I. Impact of metabolic genotypes on levels of biomarkers of genotoxic exposure. Mutat Res 2001; 482:57-69.

30. Norppa H. Cytogenetic biomarkers and genetic polymorphisms. Toxicol Lett 2004; 149:309-34.

31. Schulte PA, Pereira FP. Molecular epidemiology principles and practices. San Diego: Academic Press; 1993.

32. Albertini RJ, Anderson D, Douglas GR, Hagmar L, Hemminki K, Merlo F, et al. IPCS guidelines for the monitoring of genotoxic effects of carcinogens in humans. Mutat Res 2000; 463:111-72.

33. Bonassi S, Abbondandolo A, Camurri L, Dal Prá A, De Ferrari M, Degrassi F, et al. Are chromosome aberrations in circulating lymphocytes predictive of a future cancer onset in humans? Preliminary results of an Italian cohort study. Cancer Genet Cytogenet 1995; 79:133-5.

34. Smerhovsky Z, Landa K, Rössner P, Brabec M, Zudova Z, Hola N, et al. Risk of cancer in an occupationally exposed cohort with increased level of chromosomal aberrations. Environ Health Perspect 2001; 109:41-5.

35. Au WW, Oh HY, Grady J, Salama SA, Heo MY. Usefulness of genetic susceptibility and biomarkers for evaluation of environmental health risk. Environ Mol Mut 2001; 37:215-25.

36. Garte S. Metabolic susceptibility genes as cancer risk factors: time for a reassessment. Cancer Epidemiol Biomarkers Prev 2001; 10:1233-7.

37. Strange RC, Jones, PW, Fryer, AA. Glutathione Stransferase: genetics and role in toxicology. Toxicol Lett 2000; 112/113:357-63.

38. Knudsen LB, Norppa H, Gamborg MG, Nielsen PS, Okkels H, Soll-Johanning H, et al. Chromosomal aberrations induced by urban air pollution in humans: influence of DNA repair and polymorphisms of glutathione S-transferase M1 and Nacetyltransferase 2. Cancer Epidemiol Biomarkers Prev 1999; 8:303-10.

39. Brescia G, Celotti L, Clonfero E, Neumann HG, Forni A, Foá V, et al. The influence of cytochrome $\mathrm{P} 450 \mathrm{lAl}$ and glutathione S-transferase M1 genotypes on biomarker levels in coke-oven workers. Arch Toxicol 1999; 73:431-9.

40. Šrám R, Birkova B, Rössner P, Rubes J, Topinka J, Dejmek J. Adverse reproductive outcomes from exposure to environmental mutagens. Mutat Res 1999; 428:203-15.

41. Ichiba M, Hagmar L, Rannug A, Högstedt B, Alexandrie A-K, Carstensen U, et al. Aromatic DNA adducts, micronuclei and genetic polymorphism for CYP1A1 and GST in chimney sweeps. Carcinogenesis 1994; 15:13-52.

42. Hung RJ, Boffetta P, Brockmöller J, Butkiewicz D, Cascorbi I, Clapper ML, et al. CYP1A1 and GSTM1 genetic polymorphisms and lung cancer risk in Caucasian non-smokers: a pooled analysis. Carcinogenesis 2003; 24:875-82. 
43. Schulte PA. Opportunities for the development and use of biomarkers. Toxicol Lett 1995; 77:25-9.

44. Jekel JF, Elmore JG, Katz DL. Epidemiologia, bioestatística e medicina preventiva. Porto Alegre: Editora Artmed; 2002

45. Szklo M, Nieto FJ. Epidemiology: beyond the basis. Gaithesburg: Aspen Publication; 2000.

46. Symanski E, Greeson NMH. Assessment of variability in biomonitoring data using a large database of biological measures of exposure. AIHA J 2002; 63:390-401.

47. Suter GW. Ecological risk assessment. Boca Raton: Lewis Publishers; 1993.

48. Dubé M, Munkittrick K. Integration of effectsbased and stressor-based approaches into a holistic framework for cumulative effects assessment in aquatic ecosystems. Human and Ecological Risk Assessment 2001; 7:247-58.

49. Moore MN, Depledge MH, Readman JW, Paul Leonard DR. An integrated biomarker-based strategy for ecotoxicological evaluation of risk in environmental management. Mutat Res 2004; 552:247-68.

50. National Academy of Sciences. Risk assessment in the federal government: managing the process. Washington DC: National Academy Press; 1983.

51. Bonassi S, Au WW. Biomarkers in molecular epidemiology studies for health risk prediction. Mutat Res 2002; 511:73-86.

52. Bonassi S, Ugolini D, Kirsch-Volders M, Stromberg U, Vermeulen R, Tucker JD. Human population studies with cytogenetic biomarkers: Review of the literature and future prospectives. Environ $\mathrm{Mol}$ Mutagen 2005; 45:258-70.

53. Tucker JD. Sensitivity, specificity, and persistence of chromosome translocations for radiation biodosimetry. Mil Med 2002; 167:8-9.

54. Hayes RB, Smith CO, Huang WY, Read Y, Kopp WC. Whole blood cryopreservation in epidemiological studies. Cancer Epidemiol Biomarkers Prev 2002; 11:1496-8.

55. Beck JC, Beiswanger CM, John EM, Satariano E, West D. Successful transformation of cryopreserved lymphocytes: a resource for epidemiological studies. Cancer Epidemiol Biomarkers Prev 2001; 10:551-4.
56. Cheng L, Wang LE, Spitz MR, Wei Q. Cryopreserving whole blood for functional assays using viable lymphocytes in molecular epidemiology studies. Cancer Lett 2001; 166:155-63.

57. Smerhovsky Z, Landa K, Rössner P, Juzova D, Brabec $\mathrm{M}$, Zudova $\mathrm{Z}$, et al. Increased risk of cancer in radon-exposed miners with elevated frequency of chromosomal aberrations. Mutat Res 2002; 514:165-76.

58. Toraason M, Albertini R, Bayard S, Bigbee W, Blair A, Boffetta P, et al. Applying new biotechnologies to the study of occupational cancer: a workshop summary. Environ Health Perspect 2004; 112:413-6.

59. Bonassi S, Znaor A, Norppa H, Hagmar L. Chromosomal aberrations and risk of cancer in humans: an epidemiologic perspective. Cytogenet Genome Res 2004; 104:376-82.

60. Neri M, Ugolini D, Bonassi S, Fucic A, Holland N, Knudsen LE, et al. Children's exposure to environmental pollutants and biomarkers of genetic damage. II. Results of a comprehensive literature search and meta-analysis. Mutat Res 2006; 612: 14-39.

61. Neri M, Bonassi S, Knudsen LE, Sram RJ, Holland $\mathrm{N}$, Ugolini D, et al. Children's exposure to environmental pollutants and biomarkers of genetic damage I. Overview and critical issues. Mutation Research 2006; 612:1-13.

62. Steinemann AC. Human exposure, health hazards, and environmental regulations. Environ Impact Assess Rev 2004; 24:695-710.

63. Lopes WA, Andrade JB. Fontes, formação, reatividade e quantificação de hidrocarbonetos policíclicos aromáticos (HPA) na atmosfera. Quím Nova 1996; 19:497-516.

64. Pereira Netto AD, Moreira JC, Dias AEXO, Arbilla G, Ferreira LFV, Oliveira AS, et al. Avaliação da contaminação humana por hidrocarbonetos policíclicos aromáticos (HPAs) e seus derivados nitrados (NHPAs): uma revisão metodológica. Quím Nova 2000; 23:765-73

Submitted on 05/May/2006

Final version resubmitted on 19/Nov/2007

Approved on 04/Dec/2007 